\title{
LA RELIGIÓN EN LA ESCUELA: CULTURA, ENSENAANZA Y SÍMBOLOS RELIGIOSOS *
}

\author{
Daniel Gamper \\ Universitat Autònoma de Barcelona
}

RESUMEN. Tras exponer algunos debates políticos sobre la presencia de la religión en las instituciones educativas, así como la jurisprudencia al respecto, se repasan las ideas de J. S. MILL sobre la enseñanza, con la finalidad de ofrecer un marco normativo de la educación liberal. A continuación se presentan los casos concretos de Italia, Francia y Estados Unidos, referidos a la enseñanza, confesional o no, de la religión en los planes de estudio oficiales. En la última sección se contrapone el modelo de la enseñanza confesional al de la enseñanza del hecho religioso, y los presupuestos filosófico-políticos de ambas alternativas.

Palabras clave: enseñanza religiosa, escuela, laicidad

ABSTRACT. First, the paper states some distinct political debates on the presence of religion in educational institutions and some relevant case law on this issue. In the second section, the paper deals with J. S. MıL's ideas on education, in order to provide a normative framework of liberal education. The following sections deal with the specific ways in which Italy, France and USA treat the education, religious or not, of religions in the curricula. The final section contrasts the religious education model, on the one hand, and the teaching of the "religious fact» model, on the other; as well as the philosophical and political assumptions of both alternatives.

Keywords: religious education, school, secularism.

* Fecha de recepción: 23 de febrero de 2010. Fecha de aceptación: 5 de marzo de 2010.

Este trabajo se enmarca en el proyecto del MICINN, «La religión en el espacio público democrático. Formas de laicidad» (FFI2009-07433). Agradezco los certeros comentarios y la ayuda prestada de los profesores Laura Cappuccio y Àlex Seglers. 


\section{INTRODUCCIÓN}

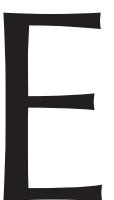

n los últimos años se han acrecentado los debates sobre la presencia de la religión en la escuela. Se ha discutido sobre la legitimidad de la exposición de símbolos religiosos, la pertinencia de la enseñanza confesional o la importancia del estudio de la cultura religiosa. Estos debates se enmarcan en un contexto sociocultural caracterizado, según algunos autores, por una creciente desecularización ${ }^{1}$. Sea o no correcto este diagnóstico sociológico, lo que se constata es que países con una consistente tradición laicista institucional, como Francia o Estados Unidos ${ }^{2}$, han contemplado la necesidad de introducir en los temarios escolares cursos sobre cultura religiosa o historia de las religiones, animados por la voluntad de contribuir desde la escuela a la armonía social y al conocimiento recíproco en sociedades crecientemente diversas.

En el presente artículo se presentan algunos debates político-culturales a propósito de la relación entre las instituciones escolares y la religión, y se resigue la jurisprudencia al respecto, con la intención de mostrar las tensiones principales que se manifiestan. En primer lugar (2), se repasan las ideas de J. S. MiLL sobre la enseñanza, con la finalidad de ofrecer un marco normativo de la enseñanza liberal, es decir, de una enseñanza que respete los derechos individuales y que acote las competencias del Estado, sin desatender las exigencias igualitaristas. En segundo lugar (3), se comenta el caso italiano a propósito de la presencia del crucifijo en las aulas, tanto a partir de las sentencias del Consejo de Estado italiano, como de la reciente decisión de la Corte Europea de Derechos Humanos. También se resigue el estatuto de «no-obligación» de los alumnos que deciden no seguir los cursos de educación religiosa confesional ofrecidos en las escuelas públicas italianas. La propuesta de introducir cursos de cultura religiosa, de historia de las religiones o de estudio del hecho religioso, tanto en Estados Unidos como en Francia, será tratada en la sección 4, en la que también se apuntan los límites a la intervención estatal en las escuelas en relación con la religión. En la última sección (5), se resumen las diversas posiciones presentadas, para señalar, desde una perspectiva normativa filosóficopolítica, cuáles son los problemas que en cada caso se intentan solventar, y, atendiendo al contexto sociológico presente, indicar los nuevos retos implícitos en la educación de ciudadanos demócratas que, al mismo tiempo, disfrutan de libertad religiosa.

\section{J. S. MILL SOBRE LA ENSEÑANZA}

El interés de MiLL por la religión se circunscribe, en lo esencial, a la importancia de la libertad religiosa, la cual es un índice de la salud de las libertades en una sociedad.

${ }^{1}$ Cfr., entre otros, J. HABERMAS, «Die Revitalisierung der Weltreligionen - Herausforderung für ein säkulares Selbstverständnis der Moderne?» en id., Philosophische Texte. Kritik der Vernunft, vol. 5, Francfort, Suhrkamp, 2009, 387-407; J.-P. WILlaIME, Le retour du religieux dans la sphère publique. Vers une laïcité de reconnaissance et de dialogue, Lyon, Editions Olivétan, 2008; Ch. TAYLOR, A Secular Age, Cambridge (Mass.), Harvard University Press, 2007; P. L. BERGER, «The Desecularization of the World: A Global Overview», en id. (ed.), The Desecularization of the World. Resurgent Religion and World Politics, Ethics and Public Policy Center, Grand Rapids, 1999, 1-18; J. CASANOVA, Religiones públicas en el mundo moderno, Madrid, PPC, 2000.

2 Vale decir que, en puridad, la tradición estadounidense más que laicista es de «no establecimiento». 
Con este espíritu liberal se enfrenta, pues, al fenómeno religioso: «Es perfectamente posible que la religión pueda ser moralmente útil, sin ser por ello intelectualmente concebible. Y sería gran prueba de prejuicio el que una persona no creyente negase que ha habido épocas y que hay todavía individuos y naciones para quienes la religión tiene utilidad» $(405 / 51)^{3}$. MiLL no se acerca de manera acrítica a las religiones, como lo demuestra que les reproche que se apoyen excesivamente en el poder coercitivo de la mayoría moral. Pero eso no le lleva a negarles toda utilidad y, por consiguiente, cierto contenido de verdad.

El texto de MiLl en el que se trata de manera más exhaustiva la cuestión de la educación es la «Inaugural Address Delivered to the University of St. Andrews» de $1867^{4}$. En ella, sostiene que todo lo que contribuye a formar al ser humano, a hacer del individuo lo que es y evita que se convierta en lo que no es, forma parte de su educación. En concreto, el concepto de educación con el que decide operar es más estrecho, se trata de «la cultura que cada generación se propone dar a los que deben sucederla de modo que sean capaces, por lo menos, de mantener, y si es posible aumentar, el nivel de mejora que se ha alcanzado» (218).

MiLl se centra en las diversas disciplinas que pueden ser enseñadas en las escuelas. En primer lugar, sostiene que el conocimiento de lenguas extranjeras es relevante, pues contribuye a que los alumnos expandan sus mentes y aprendan a imaginarse otras opciones vitales que aquellas que le han sido dadas. La ciencia debe formar parte también de los planes de estudio, pues contribuye a un mejor conocimiento de las leyes del mundo, lo cual nos permite interactuar con él de manera más racional, es decir, adaptando mejor nuestros medios a las finalidades que perseguimos. La familiaridad con los procesos científicos de búsqueda de la verdad crea ciudadanos mejor preparados para ejercer un sano escepticismo cuando se hallan, por ejemplo, ante conclusiones políticas basadas exclusivamente en la observación superficial de algunos hechos. Así pues, una ciudadanía informada, democrática, capaz de ejercer sus derechos positivos y negativos con responsabilidad, requiere un sistema de enseñanza que los capacite para poder determinar por sí mismos la verdad o falsedad de las afirmaciones relevantes.

Por lo que se refiere a la enseñanza de la política, destaca su afirmación de que la «educación sobre esta disciplina no tiene derecho a recomendar un conjunto de disciplinas basadas en la autoridad de una ciencia establecida. Pero puede aportar al estudiante materiales para su propio intelecto, ayudarle a usarlos» (244). Este conocimiento es especialmente válido pues tiene un efecto determinante en las «obligaciones de la ciudadanía» (245).

En las últimas páginas de esta lección inaugural se trata de la educación moral y religiosa. «La educación moral y religiosa consiste en el entrenamiento de los senti-

3 J. S. Mill, «The Utility of Religion», en The Collected Works of John Stuart MILL, Volume X - Essays on Ethics, Religion, and Society, en J. M. Robson (ed.), Toronto-London, University of Toronto Press-Routledge and Kegan Paul, 1985 (en adelante CW). Sigo, en parte, la traducción española: J. S. MiLl, La utilidad de la religión, Madrid, Alianza, 2009. La paginación de las citas se incluye en el texto: en primer lugar la edición original seguida de la traducción castellana.

4 «Inaugural Address Delivered to the University of St. Andrews», en CW XXI, 215-257. Ciertamente, la lección inaugural va destinada de manera eminente a la educación universitaria escocesa, pero, como afirma el mismo autor, gran parte de sus consideraciones son aplicables a la educación básica de los menores. 
mientos y los hábitos cotidianos y éstos, en su mayoría, son inaccesibles al control de la educación pública. Es el hogar, la familia, la que nos da la educación moral o religiosa que realmente recibimos. [...] La influencia moral o religiosa que puede ejercer la universidad consiste menos en una enseñanza explícita que en el tono dominante del lugar. Sea lo que sea que se enseñe, debe hacerlo penetrada por el sentido de la obligación con el doble propósito de hacer que cada uno de nosotros sea útil para sus congéneres y de elevar el carácter de la especie misma, exaltando y dignificando nuestra naturaleza» (247 y ss.).

La religión, reitera MiLl, es un asunto que compete primordialmente a las familias, por lo que las instituciones educativas deben limitarse a dar «información» (249). A continuación se pregunta de manera retórica: «¿Por qué debería ser imposible que esa información de enorme valor sobre asuntos conectados con la religión pudiera ser expuesta a las mentes de los estudiantes, que se los familiarizara con una parte tan importante del pensamiento nacional, y con las tareas intelectuales de las generaciones pasadas, como las relativas a la religión, sin enseñar de manera dogmática las doctrinas de cualquier iglesia o secta?» (id.). Dado que hay diversidad religiosa, el docente no puede caer en el dogmatismo, sino en la investigación, en la presentación de lo que actualmente se llama el «hecho religioso». La enseñanza no puede ser unilateral, sino que debe aportar la información para que los futuros ciudadanos puedan tomar sus propias decisiones en conciencia y con conocimiento de causa.

Según MiLl, es importante que las universidades prosigan con el entrenamiento en la especulación libre que la educación debe afianzar en los niños. Es cierto, sostiene, que gran parte de las grandes especulaciones de la humanidad se han dado en ambientes hostiles a la libertad (algo, por otra parte, sostenido también por BERLIN, en clave crítica con Mill, en su famoso ensayo «Two Concepts of Liberty») ${ }^{5}$. La libertad de pensamiento que constituye una de las piezas centrales del liberalismo milliano, y que junto con la libertad de expresión es uno de los elementos que mejor puede favorecer el progreso de la humanidad, es ampliada hasta abarcar la cuestión de la religión. No sólo las ciencias experimentales, ni las ideas políticas, saldrán ganando si admiten la discrepancia en su seno, sino que también las sectas religiosas pueden salir beneficiadas si en su interior se da una variedad de posiciones doctrinales. Tanto es así, que cerca ya de la conclusión de su lección inaugural, MiLL invita a los clérigos que no se sienten perfectamente representados por la fe de su orden religiosa, a no abandonarla, pues si lo hicieran ésta quedaría en manos «de los que adoptan la lectura más estrecha, más literal, y puramente textual de los dogmas; aquellos que aunque no son necesariamente intolerantes, tienen la gran desventaja de que sus aliados son los intolerantes, y que por muy grandes que sean sus méritos, y suelen ser grandes, si la iglesia es mejorable, no son las personas más adecuadas para mejorarla. Por ello, si no fuera una impertinencia por mi parte aconsejar en esta cuestión, diría que se permita que todos los que puedan

${ }^{5}$ Dicho de pasada, esta afirmación de MiLL parece resolver la objeción realizada por I. BERLIN a propósito de Sobre la libertad, a saber, MiLL reconoce aquí que la inexistencia de interferencia no es siempre equivalente a un progreso de la humanidad, de modo que no es un requisito necesario, como parece apuntarse en Sobre la libertad, sino que en ocasiones se puede dar un progreso en algún ámbito del saber sin que se den las condiciones de libertad que MiLL considera imprescindibles en la citada obra. Cfr. I. BERLIN, «Dos conceptos de libertad», en Cuatro ensayos sobre la libertad, Madrid, Alianza, 1998, 227 y ss. 
hacerlo en conciencia, que permanezcan en la iglesia. Una iglesia es mucho más mejorable desde dentro que desde fuera» $(251)^{6}$.

Las ideas expresadas en esta conferencia inaugural no discrepan mucho de lo expuesto siete años antes en su obra más influyente para el pensamiento liberal, Sobre la libertad ${ }^{7}$. La última sección del libro contiene preciosas anotaciones sobre la educación y las insiere en consideraciones sobre la libertad que prosiguen, corrigen y especifican las posiciones teóricas avanzadas al principio, en concreto, el principio de libertad según el cual sólo se puede limitar la libertad de las personas para evitar un daño, siendo cualquier otro límite estatal o social ilegítimo. En concreto, MiLl se encarga de delimitar las competencias del Estado en las cuestiones familiares. Al respecto introduce un importante matiz en la aplicación del principio de libertad: «El Estado, en tanto que respeta la libertad de cada uno en lo que especialmente le concierne, está obligado a mantener una vigilante intervención sobre el ejercicio de todo poder que permita a cualquier persona disponer de otras personas» ${ }^{8}$. Se refiere MiLL a la dominación masculina sobre las mujeres en el ámbito doméstico, la cual no debe ser vista como una cuestión de libertad sino como una de poder. En los hogares se consolida la injusticia y corresponde al Estado aliviarla. Se trata, por tanto, de un asunto que no queda bajo la protección del principio de libertad ${ }^{9}$. A continuación dedica MiLL tres páginas a la cuestión de la educación, la cual es considerada una obligación cuyo cumplimiento, en el caso de que no sea satisfecho por los padres, es competencia que recae en el Estado.

Según MiLL, el Estado debe imponer esta obligación y garantizar, con ayudas para los que las necesiten, que se cumpla con ella. No está obligado a ofrecer una educación, sino a exigir que todos la tengan. Dada la natural desconfianza con la que el liberalismo contempla las intervenciones estatales, no extraña que MiLL distinga entre la exigencia ciudadana de que los padres garanticen una educación para sus hijos, asunto que debe ser supervisado por el Estado, de una parte, y la estipulación estatal de cuáles deben ser los contenidos de esa educación obligatoria, de la otra. Si el Estado se ocupa de los

${ }^{6}$ Algo semejante encontramos en La utilidad de la religión: «Una de las tareas más onerosas que han recaído sobre los buenos poderes de la naturaleza humana ha sido precisamente la de mejorar la religión misma» (406/54). De ahí que proponga una Religión de la Humanidad que, desprovista de los elementos sobrenaturales de las religiones tradicionales, cumpliría mejor («una religión mejor» (422/100)) con el cometido de orientar «las emociones y los deseos hacia un objeto ideal reconocido como algo excelente en grado sumo y como algo que tiene absoluta supremacía sobre todos los objetos egoístas del deseo» (422/99).

7 Entendemos por pensamiento liberal aquí el que defiende básicamente la libertad de expresión y de pensamiento, así como otras libertades fundamentales. Sin duda, para un liberalismo económico estricto, la teoría de Mill peca de intervencionismo estatal, por lo que se refiere a los asuntos fiscales, así como a la promoción de una igualdad que es condición de posibilidad del pleno desarrollo de la individualidad de los individuos. Algunos liberales de cuño radical consideran que las tesis millianas están más cerca de la socialdemocracia que del liberalismo económico. Para las finalidades del presente artículo, se considera que la teoría de MitL es liberal, en la medida en que piensa que el libre intercambio de conocimientos y de opiniones entre los ciudadanos promueve el progreso de la sociedad, respeta la autonomía de los individuos y es índice de satisfacción de los deseos de los individuos.

8 On Liberty en CW XVIII, 301. Sigo en parte la traducción de Sobre la libertad, Madrid, Alianza Editorial, 1970: 192.

9 MiLl prefigura aquí la crítica feminista a la separación liberal entre privado y público, asunto en el que ahondará a propósito de su célebre, The Subjection of Women. En la última sección se abordarán los límites de la distinción público-privado a propósito de los derechos de los padres a que se respeten sus decisiones relativas a la educación religiosa y moral de sus hijos. 
contenidos de la educación, entonces aparece la amenaza de la uniformidad social que ahoga las singularidades humanas y detiene el progreso social. La solución consiste en que el Estado provea la educación sólo ahí donde la iniciativa privada no alcanza.

«Para evitar que el Estado ejerza, a través de estos arreglos, una influencia nociva sobre la opinión, los conocimientos requeridos para pasar un examen [...] se limitarían, aun en los cursos más avanzados, a hechos y ciencias positivas exclusivamente. Los exámenes sobre religión, política, u otras materias objeto de discusión, no versarán sobre la verdad o falsedad de las opiniones, sino sobre la cuestión de becho de que tal opinión es sostenida, con tales fundamentos, por éstos o los otros autores, o escuelas o iglesias» (303/195 y ss., mi cursiva). Al mismo tiempo que considera imprescindible el conocimiento del, así llamado, «hecho religioso», MiLl escribe que «nada impediría que se les enseñara religión, si sus padres así lo desean, en las mismas escuelas en las que reciben la enseñanza de las otras materias» (303/196). O sea, se respeta el derecho de los padres a que las instituciones educativas les ayuden a transmitir la religión de su elección, pero al mismo tiempo se familiariza a todos los niños con los contenidos básicos de las religiones, llegando incluso a afirmar que «ninguna objeción razonable puede hacerse a que un ateo sea examinado sobre las pruebas del cristianismo, con tal que no se le exija creer en ellas» (304/196).

Esta sección final de Sobre la libertad es especialmente interesante, porque se adentra en los problemas de aplicación del principio del daño que preside toda la obra. La cuestión de la intervención del Estado en la educación de los niños es, sin duda, motivo de disputa, pues la sola obligación de que todos los niños cumplan con unos requisitos mínimos puede ser vista como una limitación de la libertad negativa de los padres. Sin embargo, y como señala V. CAMPS ${ }^{10}$, para entender cabalmente el concepto de libertad milliano hay que utilizar también el concepto de libertad positiva, pues para poder ejercer la libertad es preciso disponer de los medios necesarios, no sólo medios materiales, sino también intelectuales y espirituales, los cuales deben ser garantizados por el Estado.

En esta somera mirada a las consideraciones de MiLL sobre religión, se ha evidenciado el vínculo de la educación con los deberes de ciudadanía de los futuros ciudadanos. El asunto de la religión en las escuelas es enfocado por MiLL con igual respeto para la libertad religiosa negativa que para la positiva, por usar la terminología acuñada por BERLIN. A saber, de una parte, al optar por una educación del hecho religioso y por una evaluación que no atañe a aspectos doctrinales sino sólo fácticos, se garantiza el derecho de los padres a educar a sus hijos en la religión de su elección o de su tradición. La libertad negativa queda también protegida en la medida en que el Estado no suscribe una única religión, sino que ofrece un abanico de las presentes en la sociedad diversa. Por lo que se refiere a la libertad religiosa positiva, la educación en los hechos de las diversas religiones permite que los futuros ciudadanos que así lo deseen puedan elegir la religión que en conciencia mejor les parezca, o no elegir ninguna, claro está, teniendo un conocimiento de las diversas opciones entre las que pueden elegir.

10 A propósito de MiLl, CAmps define la libertad positiva como «la capacidad de cada uno para liderar su comportamiento más allá no ya de las leyes positivas, sino de costumbres, modas, inercias y presiones sociales que tratan de homogeneizar a las personas en lugar de individualizarlas», V. CAMPS, Introducción a la filosofía política, Barcelona, Crítica, 2001, 72 y ss. 


\section{SÍMBOLOS RELIGIOSOS Y EDUCACIÓN RELIGIOSA SIN ALTERNATIVAS: EL CASO EN ITALIA}

A finales de 2009, la Corte Europea de Derechos Humanos (CEDH) sentenció la ilegitimidad de la presencia de crucifijos en las aulas de las escuelas públicas italianas, resolviendo así la demanda de la ciudadana Solie Lautsi que, tras agotar todos los recursos jurídicos de Derecho nacional, se dirigió a la CEDH para que estableciera si la presencia del crucifijo en el aula violaba algunos derechos fundamentales. Según la sentencia, «la presencia del crucifijo puede fácilmente ser interpretada por los alumnos de todas las edades como un signo religioso y se sentirían educados en un entorno escolar marcado por una religión dada. [...] La libertad negativa no se limita a la ausencia de servicios religiosos o de enseñanza religiosa. Incluye las prácticas y los símbolos que expresan, en particular o en general, una creencia, una religión o el ateísmo. [...] La Corte no ve de qué manera la exposición en las aulas de las escuelas públicas de un símbolo que puede ser razonablemente asociado al catolicismo (la religión mayoritaria en Italia) podría servir al pluralismo educativo que es esencial para la preservación de una "sociedad democrática" tal y como la concibe la Convención. [...] La Corte estima que la exposición obligatoria de un símbolo de una confesión dada en [...] las aulas restringe el derecho de los padres a educar a sus hijos según sus convicciones, así como el derecho de los niños escolarizados a creer o a no creer. La Corte considera que esta medida comporta una violación de estos derechos, pues las restricciones son incompatibles con el deber que incumbe al Estado de respetar la neutralidad en el ejercicio de la función pública en particular en el ámbito de la educación» (Lautsi vs. Italia, r. 30814/06, 3 de noviembre de 2009) ${ }^{11}$.

De este modo se contradecía lo declarado por el Consejo de Estado italiano en 2006 que se preguntaba si «la exposición del crucifijo en las aulas escolares es incompatible con el principio de la laicidad del Estado» (Consiglio di Stato, Sen. núm. 556/06). En su sentencia, el Consejo de Estado sostenía que el significado del crucifijo depende del lugar en el que se expone: «En sede no religiosa, como la escuela, destinada a la educación de los jóvenes, el crucifijo posee para los creyentes un valor religioso, pero para creyentes y no creyentes su exposición estará justificada y asumirá un significado no discriminatorio desde el punto de vista religioso, si es capaz de representar y de referirse de manera sintética inmediatamente perceptible e intuible a valores cívicos relevantes, y, en concreto, a los valores que subyacen e inspiran el orden constitucional, fundamento de nuestra convivencia cívica. En este sentido el crucifijo podrá desem-

11 Esta decisión coincide con la del Tribunal de lo Contencioso-Administrativo núm. 2 de Valladolid, que consideró que el Consejo Escolar vulneraba algunos derechos fundamentales al permitir la exposición en el colegio de un crucifijo, dado que «la presencia de estos símbolos en estas zonas comunes del centro educativo en el que reciben educación menores de edad en plena fase de formación de su voluntad e intelecto, puede provocar en éstos el sentimiento de que el Estado está más cercano a las confesión con la que guardan relación los símbolos presentes en el centro público que a otras confesiones respecto de las que no está presente ningún símbolo en el centro público, con lo que el efecto que se produce [...] es la aproximación a la confesión representada en el centro por considerar que es la más próxima al Estado y una forma de estar próximo a éste» (Sent. 288/2008). Para una panorámica del debate sobre símbolos religiosos en la escuela cfr. À. SEGLERS, «El xoc en la cultura legal doméstica. Del crucifix cristià al vel musulmà», Idees. Revista de Temes Contemporanis, núms. 23/24, 2004, 172-180. 
peñar, también en un horizonte "laico", distinto del religioso que le es propio, una función simbólica altamente educativa, con independencia de la religión profesada por los alumnos». El hecho de que mediante el crucifijo se apunte al origen religioso de los valores constitucionales, no va en detrimento de la autonomía «del orden temporal en relación con el orden espiritual», pues se trata de valores que pueden «ser sancionados "laicamente" por todos, independientemente de si se adhieren a la religión que los ha inspirado y propugnado». Se entiende que el crucifijo simboliza «los valores sobre los que se funda el Estado» y que es el instrumento idóneo para expresar de la manera más eficaz posible estos valores.

Los símbolos religiosos en las aulas, o más en concreto, el crucifijo es cultura, se sentencia. Forma parte de la cultura del país y para comprender el lugar en el que se vive, es preciso familiarizarse con él. No es, así pues, un símbolo exclusivamente religioso, sostiene la sentencia, sino algo cultural. Siendo cultural, la libertad religiosa negativa de los alumnos no se ve comprometida, pues la cruz sólo cumple la función de enfatizar el contexto cultural, el lugar en el que se está, a saber, Italia. La cruz se convierte en un signo nacional cuya conservación es crucial, valga la redundancia, para que perdure la nación. La escuela se convierte así en forjadora de italianos que aseguran el futuro de los rasgos distintivos del Estado-nación, de la República. Una traza cultural y política de origen religioso que debe ser asimilada en el proceso de integración a la República ${ }^{12}$.

Sin embargo, al mismo tiempo, existen instrumentos normativos, avalados por la Corte Constitucional italiana, que modulan la laicidad de modo que no se vulnere tout court la libertad religiosa negativa de los alumnos. Es el caso de la sentencia sobre la obligatoriedad de la enseñanza religiosa en las escuelas en la que se establecen los términos en que deben ser acogidos los estudiantes que no deseen participar en estas lecciones ${ }^{13}$. El contenido de lo que pueden hacer los alumnos que no hacen uso de la hora de religión ${ }^{14}$ es elegido libremente por éstos, de manera que no haya una obligación alternativa. A diferencia de la República Federal Alemana, en donde las lecciones de religión y de ética son alternativas excluyentes (modelo que también se aplicó en España durante la década de 1980), en Italia no se concibe que la decisión de no participar en la hora de religión implique obligaciones alternativas, sino un «stato di non-obbligo» que podría permitir incluso, según la circular de la Administración, que los alumnos se ausentaran de la escuela durante la enseñanza religiosa. Con este matiz

12 La perspectiva católica al respecto insiste en señalar que la ideología multicultural «que legitima otros símbolos o presencias religiosas», en concreto, todo lo relativo al Islam, va en detrimento de la laicidad en tanto que «limita y borra los símbolos y la presencia cristiana», cfr. C. CARDIA, «La laicità in Italia». en F. D’AGOSTINO (ed.), Laicità cristiana, Milano, San Paolo, 2007, 39-56, aquí 55.

${ }^{13}$ La educación religiosa católica en las escuelas públicas italianas viene avalada por el art. 9.2 de la Ley de 25 de marzo de 1985, núm. 121, que modificaba los Pactos Lateranenses: «La República italiana, reconociendo el valor de la cultura religiosa y tomando en consideración que los principios del catolicismo forman parte del patrimonio histórico del pueblo italiano, seguirá garantizando, en el cuadro de la finalidad de la escuela, la enseñanza de la religión católica en las escuelas públicas [...]. Respetando la libertad de conciencia y la responsabilidad educativa de los padres, queda garantizado a todos el derecho de elegir inscribirse o no inscribirse en la enseñanza mencionada. En el acto de inscripción, los alumnos o sus padres ejercitarán este derecho sin que su elección pueda suponer ninguna forma de discriminación».

${ }_{14}$ Cfr. el film de M. BELlocCHIO, L'ora di religione, en el que se ofrece una visión asfixiante de las altas esferas católicas y masónicas romanas, usando como pretexto los sucesos acaecidos al padre de un niño, cuya madre ha inscrito en la hora de religión para granjearse el beneplácito del Vaticano. 
se persigue «no hacer que la enseñanza de religión católica y otro compromiso escolar sean equivalentes, para no condicionar desde el exterior de la conciencia individual el ejercicio de una libertad constitucional, como la religiosa, que implica a la interioridad de la persona» (Corte Costituzionale, 13/1991) ${ }^{15}$.

Mientras que la sentencia a favor de la presencia del crucifijo en las escuelas parece forzar en exceso el principio de separación Estado-confesiones religiosas propio de la laicidad, la definición del «stato di non-obbligo» protege de discriminación a los alumnos que no desean inscribirse a las asignaturas de educación católica. Al no tratarse de dos alternativas mutuamente excluyentes se evita el riesgo de colocar a un mismo nivel la enseñanza religiosa y otra cualquiera, garantizándose así la libertad de la decisión religiosa, así como de la no religiosa. Se observa, por tanto, que cierta confesionalización de las instituciones públicas como la escuela es acompasada y atenuada por medidas que garanticen la libertad religiosa de los alumnos. Se trata de un arreglo de la laicidad que se esfuerza por que la adscripción estatal a la confesión católica no vaya en menoscabo de la libertad religiosa (o libertad respecto de la religión) de las minorías. Como se verá más adelante, a propósito de la propuesta de M. Nussbaum, el arreglo italiano tiene serias dificultades para armonizar la igualdad de todos los afectados.

\section{EL ÉNFASIS EN LA SEPARACIÓN: LOS CASOS FRANCÉS Y ESTADOUNIDENSE}

\subsection{Francia}

La Constitución francesa es la única en Europa que incluye el concepto «laicidad» en su ordenamiento, en concreto en el art. 1 de su Constitución: «Francia es una República indivisible, laica, democrática y social» (art. 1) ${ }^{16}$. Esta laicidad ha adoptado diversas formas desde su positivación en $1905^{17}$. La ausencia de símbolos religiosos estáticos en las escuelas ha sido una constante a la que, en el último lustro, se ha añadido la prohibición de que los alumnos porten símbolos religiosos ostensivos, en clara alusión a los velos propios del Islam. Al mismo tiempo, se plantea la necesidad de introducir cursos de cultura religiosa en las aulas.

Para nuestros intereses resulta relevante la definición propuesta por R. DÉBRAY en un informe enviado al ministro de educación en 2002 a propósito de la educación del hecho religioso en las escuelas públicas francesas: «El principio de laicidad sitúa la libertad de conciencia (la de tener o no una religión) en un lugar superior a lo que en algunos países se llama la libertad religiosa (la de poder elegir una religión en el supuesto de que se tenga una) ${ }^{18}$. En este sentido la laicidad no es una opción espiritual

15 Cfr. también Corte Costituzionale, 203/1989. La reciente jurisprudencia española al respecto se ha inclinado por no considerar necesario que existan «actividades de estudio alternativas» a la religión cuyo contenido se refiera a «la docencia moral» (À. SEGLERS, La laicidad y sus matices, Granada, Comares, 2005, 87).

16 Vid. también el art. 2 de la Ley de 1905 sobre la separación iglesias-Estado: «La República no reconoce, ni financia, ni subvenciona ningún culto».

17 Cfr. J. BAUBÉROT, Lä̈cité 1905-2005, entre passion et raison, Paris, Seuil, 2004.

18 Es destacable que DEBRAY hable de libertad de conciencia y no de libertad religiosa, y que considere, como por otra parte es habitual, que la primera es más englobante que la segunda, pues incluye también a 
entre otras, sino que es lo que hace posible su coexistencia, pues lo que es común a todos los hombres debe tener preeminencia sobre lo que los separa efectivamente. La facultad de acceder a la globalidad de la experiencia humana, inherente a todos los individuos dotados de razón, implica la lucha paulatina contra el analfabetismo religioso y el estudio de los sistemas de creencias existentes. Por ello no se puede separar el principio de laicidad del estudio de lo religioso» ${ }^{19}$.

El informe de DÉBRAY retoma una discusión iniciada en 1990 a partir de un debate desencadenado con motivo de un informe encargado por el ministro de Educación al historiador Ph. JOUTARD, en el cual se sugería otorgar mayor importancia a la historia de las religiones en las asignaturas de historia, geografía y literatura, para garantizar que los alumnos se familiarizaran con el acervo religioso de su cultura ${ }^{20}$. Otra de las secuelas de este debate es el conocido informe redactado por la comisión Stasi en 2004 a propósito de la laicidad en la escuela francesa, en el que se avalaba un «acercamiento razonado a las religiones como hechos de civilización» para comprender mejor las diferentes culturas presentes en la sociedad francesa ${ }^{21}$.

El texto de DÉBRAY resume los nuevos desafíos de la escuela en una coyuntura sociocultural en la que confluyen circunstancias de diverso cariz: la progresiva ignorancia de la población acerca de los símbolos comunes en los que se basan gran parte de las tradiciones del país; el hecho de que la escuela pasa a desempeñar la tarea de vector de transmisión de los conocimientos necesarios para orientarse en la sociedad que antes recaía en la familia, la iglesia o la comunidad; y una creciente diversificación de la sociedad que amenaza con dificultar la coexistencia pacífica.

¿En qué medida la enseñanza del hecho religioso puede contribuir a paliar los déficits detectados por DÉBRAY? Basta observar las reacciones al mencionado informe para ver que se trata de un asunto que despierta enormes suspicacias. De una parte los laicistas consideran que esta asignatura implica una confesionalización encubierta del espacio público educativo; de la otra, los creyentes sostienen que la enseñanza de varias religiones superpuestas está al servicio del «relativismo» del presente, y que, privadas del vínculo de fe, las religiones no pueden ser correctamente comprendidas por los niños. También apuntan que se utilizan procedimientos pedagógicos que reducen lo cultual a lo cultural, y la espiritualidad y el afán de trascendencia de los hombres a una cuestión estrictamente patrimonial, es decir, a un asunto del pasado

Dado que ocupa un lugar preeminente en el ordenamiento francés, la laicidad puede ofrecernos la clave para justificar la enseñanza del «hecho religioso». El orden

aquellos que desean quedar libres de religión por motivos de conciencia. Osea, que la conciencia no es necesariamente religiosa.

19 R. DÉBRAY, L'enseignement du fait religieux dans l'École lä̈que, Paris, La Documentation Française, 2002, 19. La discusión sobre la laicidad positiva en Francia, reactivada durante la presidencia de N. SARKOZY aprovecha también este discurso favorable al fenómeno religioso, y, en ocasiones, va incluso más allá: «La República puede enriquecerse con la esperanza de los ciudadanos "creyentes", lo que no significa que estén por encima de los que no creen. Cada uno en su sitio, pero el practicante religioso no tiene que excusarse de ello y la República debe incluso velar para que pueda practicarla en buenas condiciones», N. SARKOZY, La República, las religiones, la esperanza, Madrid, Gota a Gota, 2006, 25.

${ }_{20}$ P. JOUTARD, «Enseigner l'histoire des religions», Éducation et Pédagogies, núm. 7, 1990: 81-87, aquí 83.

${ }^{21}$ Laïcité et République. Rapport au Président de la République, Commission présidée par Bernard Stasi, Paris, La Documentation Française, 2004, 137. 
laico es concebido como aquello que hace posible la coexistencia entre los diversos, y para que ésta sea efectiva se hace imperioso conocer los principios que articulan la vida ajena, sean religiosos o de otro cariz. Desde esta perspectiva, la justificación de la enseñanza de la religión en la escuela no es un instrumento para garantizar a los padres su derecho a que sus hijos reciban una educación espiritual acorde con sus creencias, ni tampoco sirve para mantener en vigor el patrimonio religioso-cultural de la sociedad Se trata, antes bien, de ampliar el conocimiento de los diversos en la sociedad, de las minorías, para enfrentarse a la creciente diversidad social. La enseñanza de historia de las religiones o del hecho religioso es vista en términos de ciudadanía, de educación para la tolerancia, de conocimiento y, por consiguiente, de respeto recíproco ${ }^{22}$.

\subsection{Estados Unidos de América}

Al igual que en el caso francés, la educación confesional está excluida de los currícula en las escuelas públicas estadounidenses, y también se plantea, de manera creciente, la necesidad de introducir estudios sobre la religión o de historia de las religiones, para paliar las carencias culturales, así como para mejorar la calidad de la democracia en una sociedad plural y diversa. Por lo que se refiere a los símbolos religiosos estáticos, huelga decir que éstos no son aceptados en las dependencias escolares, siguiendo así una tradición jurisprudencial que suele rechazar la financiación estatal de los símbolos religiosos de cualquier tipo en el espacio público ${ }^{23}$.

Una de las piezas clave sobre la enseñanza del hecho religioso en Estados Unidos es la sentencia School District of Abington vs. Schempp de 1963, en la que se dio la razón a la familia Schempp, la cual sostenía que el reglamento que imponía la lectura de diez frases de la Biblia al inicio de la jornada escolar atentaba contra la Cláusula de Establecimiento en la primera enmienda de la Constitución Americana ${ }^{24}$. En el resumen de sus conclusiones, el Tribunal Constitucional sentencia que «ninguna ley estatal o consejo escolar puede exigir que se lean pasajes de la Biblia o que se recite el Padrenuestro

22 Son interesantes las conclusiones de M. EsTIVALÈzEs, quien tras afirmar que no es imprescindible ver todo discurso sobre las religiones como un acto de proselitismo que altera la requerida neutralidad de la escuela, y que la laicidad en ningún modo excluye a las religiones como hechos culturales dignos de estudio científico, concluye que «lo importante es desarrollar una actitud de distancia de sí, de puesta en perspectiva de las propias convicciones, por ejemplo en relación con el ambiente familiar y cultural, de trabajar sobre las propias pasiones y de aprender la libertad de juicio. Puede que en esta capacidad de distancia reflexiva, sin negación ni relativismo, radique una de las misiones esenciales de la escuela republicana» (M. EsTivALĖZES, «L'enseignement du fait religieux a l'école, un faux problème?», en Spirale. Revue de Recherches en Education. «Laïcité, croyances et éducation», 2007: 93-105: 103; cfr. también id., El hecho religioso y la enseñanza laica. La experiencia francesa, Sevilla-Zamora, Comunicación social, 2008, esp. cap. 10). No es extraño que veamos aparecer aquí una de las fórmulas rawlsianas, a saber, la aplicación de la tolerancia a la filosofía misma: el filósofo debe distanciarse de las propias convicciones, debe saber que su autoridad no radica en sus convicciones, sino en los argumentos que utiliza, así como en el respeto democrático a las opiniones bien fundadas del resto de los ciudadanos.

23 Sobre la experiencia jurídica estadounidense de case law en materia de libertad religiosa, $c f r$. R. PALOMINO, Las objeciones de conciencia. Conflictos entre conciencia y ley en el Derecho norteamericano, Madrid, Montecorvo, 1994; J. I. RUBIO LÓPEZ, La primera de las libertades. La libertad religiosa en los EE.UU. durante la Corte Rehnquist (1986-2005): una libertad en tensión, Pamplona, Eunsa, 2006.

${ }^{24}$ Como es sabido, la citada cláusula en Primera Enmienda a la Constitución americana reza: «El Congreso no podrá aprobar ninguna ley conducente al establecimiento de religión alguna». 
en las escuelas públicas del Estado al inicio de todos los días escolares; incluso si todos los estudiantes pueden quedar eximidos de acudir o de participar a estos ejercicios con una petición escrita de los progenitores» ${ }^{25}$.

Las críticas a la sentencia sostienen que si no se permiten estas prácticas religiosas se acabará estableciendo una «religión secular», es decir, una disposición hostil a la religión que privilegia a los no creyentes. Es remarcable, sin embargo, que los jueces, en la misma sentencia, añadieran que «la educación no está completa sin un estudio comparativo de las religiones o de la historia de las religiones en relación con el desarrollo de la civilización. Se puede decir, sin duda, que la Biblia es digna de ser estudiada por sus cualidades literarias e históricas. Nada de lo que hemos dicho aquí indica que un estudio semejante de la Biblia o de la religión, si se presenta de manera objetiva como parte de un programa secular de educación, no pueda ser realizado de manera consistente con la Primera Enmienda. Pero los ejercicios de los que tratamos no caen en estas categorías. Son ejercicios religiosos exigidos por los estados que violan las órdenes de la Primera Enmienda según la cual el gobierno debe mantenerse estrictamente neutral, ni ayudando ni oponiéndose a la religión» ${ }^{26}$.

La práctica que la familia Schempp impugnó fue habitual cuando se fundaron las primeras escuelas públicas estadounidenses, cuando se creía que sólo era posible transmitir una moralidad pública a los niños con ayuda de la religión. A pesar de que diversas sentencias durante la primera mitad del siglo XX negaron la legitimidad constitucional de esta práctica, no desapareció completamente de los currícula escolares ni de las regulaciones de los estados, como lo demuestra que en 1962 existiera aún en Pensilvania. Pero la sentencia del caso Schempp viene a romper con esta práctica que atendía, en gran medida, a factores sociohistóricos, en concreto al anticomunismo estadounidense tras la Segunda Guerra Mundial.

Para romper con estas prácticas ilegítimas, en School District of Abington vs Schempp el juez Clark propuso un test de constitucionalidad de las decisiones estatales relativas a la religión: «El test podría plantearse como sigue: ¿cuál es el propósito y efecto principal de la ley? Si es el fomento o la inhibición de la religión, entonces la ley excede las facultades del orden legislativo tal como está limitado por la Constitución. Es decir, para acatar las limitaciones de la Cláusula de Establecimiento debe existir un propósito legislativo secular y un efecto principal que ni fomente ni restrinja la religión» ${ }^{27}$.

En un reciente libro, M. Nussbaum resigue las vicisitudes de la libertad religiosa en Estados Unidos. En él sostiene que el principio regulador de las relaciones Estadoiglesias, así como de la libertad religiosa de los ciudadanos, debe ser el de la igualdad religiosa, el cual conlleva el corolario de la imparcialidad religiosa del Estado. «La búsqueda de la igualdad [fue] lo que llevó a adoptar cambios tales como la prohibición en

25 Abington Township v. Schempp, 374 U.S. 203.

26 Abington Township v. Schempp, 374 U.S. 203, 225.

27 Abington Township v. Schempp, 374 U.S. 203, 222, citado en NussBAum, 2009: 250. En otra sentencia se refinó lo propuesto por el juez Clark. Es el, así llamado, Lemon Test, según el cual, para saber si un programa de estudios que incluye la religión es o no constitucional en Estados Unidos hay que poder responder afirmativamente a las siguientes tres preguntas: 1) ¿la práctica tiene un objetivo secular?;2) ¿el objetivo principal de la práctica no promueve ni desalienta a la religión?, y 3 ) ¿la práctica evita un vínculo excesivo con la religión? (cfr. B. Mitchell y R. E. Salsbury, Encyclopedia of Multicultural Education, Westport, Greenwood Press, 1999, 200). 
la escuela de la plegaria y de la lectura de la Biblia, no la arrogante convicción de que la religión sea algo poco significativo o marginal» ${ }^{28}$.

NussBaum defiende la igualdad de los ciudadanos para ejercer sus derechos religiosos o para no ejercerlos en el caso de que no lo consideren relevante. Para que esto sea posible, propone unas medidas gubernamentales que no discriminen por motivos religiosos o antirreligiosos, una imparcialidad religiosa que garantice que cada cual pueda seguir su conciencia, sin que eso implique que el Estado o los estados se inclinen a favor de una confesión concreta o de una opción no religiosa. La cuestión escolar sólo la trata en los casos en que se plantean dudas sobre la financiación de algunos servicios vinculados a la escuela (transporte de alumnos, ayuda a niños discapacitados, etc.), o cuando se introducen, aunque sea de manera no coercitiva, prácticas religiosas en el ámbito educativo. Su propuesta es más incisiva cuando trata de los nuevos desafíos a los que debe hacer frente la educación dada la creciente diversidad religiosa de Estados Unidos: «Muchos estadounidenses [no] saben que hay numerosas personas genuinamente religiosas que no reconocen un Ser Supremo. Conocen los nombres "budismo", "confucianismo", "taoísmo" y "universalismo unitario", pero no son conscientes de que esos credos no son teístas. Muchos de ellos también desconocen la existencia de variedades de confesiones familiares, el cristianismo y el judaísmo, que no reconocen un Dios creador personal. Todos estos hechos tienen relevancia para nuestros debates públicos sobre la religión y el Derecho y, sin embargo, nuestros sistemas educativos no han logrado transmitirlos a nuestros ciudadanos. Nuestros principios constitucionales necesitan una mayor afinación para enfrentarse a los desafíos planteados por esta nueva diversidad, y dicha afinación exigirá, a su vez, un debate público en el que los ciudadanos hablen sobre sus modos propios de hallar sentido a la vida y escuchen con respeto cosas que inicialmente encuentran extrañas y hasta molestas. Tal conversación irá mejor si la educación a todos los niveles alcanza un mayor éxito al inculcar los hechos fundamentales relativos a las distintas religiones presentes en nuestra sociedad» ${ }^{29}$.

De nuevo vemos que la defensa de la separación entre Estado y confesiones religiosas no conlleva necesariamente la desaparición de toda referencia religiosa en los currícula pedagógicos. Los desafíos de sociedades crecientemente plurales han despertado la necesidad de introducir la enseñanza de «los hechos fundamentales» de las religiones de los ciudadanos. En esto, NussBaum coincide con el documento publicado en 1988 por diversos grupos religiosos y educativos, «Religion and the Public School Curriculum», en el que se hallan las motivaciones por las que conviene un acercamiento escolar a las religiones. Los motivos son tres: el papel desempeñado por la religión en la cultura, el conocimiento y la valoración de la libertad religiosa y la promoción de la comprensión transcultural para garantizar un buen funcionamiento de la democracia y de la paz mundial. Algo que, por otra parte, ya había sido afirmado por el National Council for the Social Studies en 1984, destacando que el estudio de las religiones debía acentuar la influencia de éstas en la historia, la cultura, las artes y los asuntos contemporáneos, y que debía ser descriptivo, no confesional, y realizado en un entorno «free of advocacy» ${ }^{30}$.

28 M. Nussbaum, Libertad de conciencia, Barcelona, Tusquets, 2009, 237.

29 Nussbaum, 2009: 363 y ss.

30 Citado en J. K. Uphoff, «Religious Diversity and Education», en J. A. BanKS y Ch. A. McGeE BanKs (eds.), Multicultural Education. Issues and Perspectives, Allyn and Bacon, Needhman Heights, 1989, 87-103, 100. 


\section{RELIGIÓN Y ESCUELA: CONTROVERSIAS TEÓRICO-FILOSÓFICAS}

\subsection{Laicidades}

Como los diversos casos presentados hasta aquí han evidenciado, la laicidad no ofrece un manual de instrucciones que sea aplicable de manera mecánica, sino que requiere de medidas prudenciales para adaptarse a los contextos dados, así como a las exigencias de cada momento histórico. En general, la prudencia en la aplicación de los principios de la laicidad requiere tanto una abdicación de las aspiraciones maximalistas del laicismo, cuanto una renuncia a las ansias de trato privilegiado de las religiones mayoritarias. Esta dependencia del contexto implica que, como dice acertadamente MATABOSCH, más que de laicidad haya que hablar de laicidades ${ }^{31}$, es decir, de modelos muy diversos de relación Estado e iglesias, y de maneras diferentes de reconocer y garantizar la libertad religiosa de los ciudadanos.

La laicidad no se puede reducir a la separación Estado-confesiones religiosas. Se puede, tal vez, proponer la imparcialidad religiosa del Estado como criterio para decidir qué políticas son legítimas y cuáles no, como propone NussBAum. Un ejemplo de esta imparcialidad se halla en el ya mencionado Lemon Test, el cual es relevante, pues pone de manifiesto, de una parte, que los fundamentos constitucionales de Estados Unidos partían de la necesidad de mantener la igualdad religiosa, y, de la otra, que la aplicación de esta igualdad plantea problemas en cada caso concreto, que no pueden ser resueltos de manera expeditiva aplicando a rajatabla unos principios dados ${ }^{32}$.

El criterio será, pues, el de la igualdad de respeto a las conciencias de todos los ciudadanos. Una igualdad que obliga a que las instituciones renuncien, no tanto a una excesiva imbricación con las iglesias o con una confesión concreta (como sucede en Italia o, también, en España), cuanto a un laicismo excluyente que pretende «acabar con toda influencia cristiana en la sociedad ${ }^{33}$. Recordamos aquí la afirmación de MiLL mencionada en la primera página sobre la indiscutible utilidad de la religión, a pesar de las reservas intelectuales que al respecto se puedan tener.

\subsection{El modelo nacional: enseñanza confesional y símbolos religiosos}

El apoyo estatal a la religión católica en Italia (y también en España) responde a un modelo esencialista nacional más preocupado por mantener los rasgos distintivos del Estado-nación original que de proteger a las minorías del poder discriminador de las mayorías. Los modelos educativos que alientan la presencia de símbolos religiosos

31 A. MatabosCH, «Laïcitats, läicisme y aconfessionalitat. Models de relacions entre Església i Estat», en Idees. Revista de Temes Contemporanis, núm. 26, 2005, 136-143.

32 «Como declaró el juez Burger en el caso Lemon vs. Kurtzman [...], la línea entre la Iglesia y el Estado, "lejos de ser un muro es una barrera borrosa, indistinta y variable que depende de todas las circunstancias propias de una relación particular". Lo que sostenía Aristóteles acerca de la justicia es relevante aquí: es crucial no servirse de criterios que se apliquen mecánicamente a un contenido intrincado y cambiante», NusSBAUM, 2009: 235 .

33 R. Díaz-Salazar, España laica, Madrid, Espasa, 2008, 23. 
en las instalaciones escolares y que garantizan la continuidad de la tradición religiosa mayoritaria parten del presupuesto que la finalidad de la institución educativa consiste en ofrecer un suelo cultural común a los alumnos que les permita orientarse en la cultura en la que se encuentran. Así, el conocimiento de DANTE y su literatura puede ser considerado un elemento más de la «italianidad» junto con la tradición católica.

Es cierto que, como se ha visto, la tendencia homogeneizadora de los sistemas educativos con vocación nacional se ve atenuada por disposiciones que protegen a las minorías. Es el caso del «stato di non-obbligo» de los estudiantes que no desean hacer uso de la «hora de religión». Sin embargo, esto no basta si se adopta el punto de vista de la igualdad religiosa. Resulta en este contexto revelador lo sostenido por NuSSBAUM, a saber, que el nacionalismo esencialista europeo no presta suficiente atención a los desafíos de sociedades crecientemente plurales ${ }^{34}$.

Se diría que la pretensión uniformizadora implícita en la exhibición de símbolos religiosos estáticos, así como en el apoyo estatal a la educación confesional, es un intento de poner puertas al campo que no sólo debe ser considerada una influencia ilegítima del Estado (como sostiene la CEDH a propósito de Lautsi), que pretende travestir lo religioso con la cultura, sino que también es difícilmente justificable desde el punto de vista de las minorías sociales.

\subsection{La sociedad tolerante: el «hecho religioso»}

La breve presentación del estado de la cuestión en los contextos francés y estadounidense nos ha familiarizado con el concepto de libertad religiosa negativa, a saber, la libertad entendida como no interferencia. En ambos países se excluye la docencia de la religión en términos confesionales para garantizar que el principio de separación entre Estado e iglesias sea efectivo en el ámbito escolar. El Estado no subvenciona, ni apoya, ni distingue ninguna confesión, ni tampoco la ausencia de toda confesión. La menor intervención del Estado equivale, siguiendo estrictamente la definición de BERLIN, a mayor libertad negativa. Sin embargo, y retomando aquí las reflexiones procedentes del republicanismo, hay que tomar en consideración también la libertad entendida como no dominación, en el sentido en que hay que garantizar que las religiones mayoritarias no sometan a los grupos minoritarios, ante la pasividad o negligencia benigna de las instituciones del Estado. Algo de ello hay también en la, así llamada, «política del reconocimiento», según la cual hemos de reconocer y fomentar la particularidad, pues sólo así no constreñiremos a las personas a adaptarse a «un molde homogéneo que no les pertenece de suyo» ${ }^{35}$.

Las propuestas, cada vez más extendidas, a favor de la enseñanza del hecho religioso o de la historia de las religiones, es decir, de una educación religiosa no confesional, se enmarcan en esta tendencia a tomar en consideración las necesidades de las minorías para garantizar que no se dé una desigualdad injustificable y promovida por

\footnotetext{
34 «Acostumbrados a la idea de que todos los ciudadanos son iguales, muchos europeos han reflexionado poco sobre cómo convivir con personas que son diferentes», NussBAuM, 2009: 25.

35 Ch. TAYLOR, El multiculturalismo y «la política del reconocimiento», México, Fondo de Cultura Económica, $1993,67$.
} 
las instituciones del Estado. Sin embargo, y a diferencia de lo propuesto desde las filas comunitaristas, el deseo de subsanar el analfabetismo religioso de la sociedad no tiene como objetivo explícito el afianzamiento de las identidades particulares, sino el conocimiento recíproco entre los diversos. Ésta es la justificación mayoritariamente aceptada a favor del estudio de la diversidad religiosa, pero no carece de problemas.

En primer lugar, veamos cuáles son las objeciones elevadas por parte de los padres creyentes que consideran que el estudio objetivo e histórico de las religiones, la educación en la diversidad, los priva de poder ejercer su derecho a que sus hijos reciban la educación moral y religiosa de su agrado. Este rechazo es ilustrado por los cada vez más numerosos casos de objeción de conciencia presentados por progenitores que no desean que sus hijos sigan cursos en los que, según ellos, se contradice la fe que desean transmitir a sus hijos. En España es conocida la masiva objeción a la asignatura «Educación para la ciudadanía» que, hasta la fecha, no ha encontrado apoyo en las altas instancias judiciales (Tribunal Supremo, 11 de febrero de 2009, r. 905/2008). En Quebec, la Corte Superior de Justicia desestimó la demanda de exención de asistencia al curso de reciente creación, «Ética y cultura religiosa», de unos padres que consideraban que el contenido promovía una visión politeísta y relativista del fenómeno religioso (31 de agosto de 2009, QCCS 3875). En el ámbito europeo, destaca la sentencia de la Corte Europea de Derechos Humanos, Appell-Irrgang vs. Alemania, en la que también se rechazó la petición de exención de unos padres que consideraban que la asignatura obligatoria de ética les impedía ejercer libremente su derecho a introducir a sus hijos en la fe de su elección. Es interesante constatar que la sentencia sostiene que no existe un derecho a no escuchar opiniones que contradicen las propias (6 de octubre de 2009, r. $45216 / 07)^{36}$.

Los progenitores que se han opuesto a que sus hijos asistan a lecciones en las que se pueden ver confrontados con contenidos que contradicen aquellos que les han sido aportados en el hogar no han encontrado apoyo en las instancias judiciales. Estas sentencias ponen de manifiesto que la disonancia cognitiva que experimentan los hijos no es motivo suficiente para eximirlos del conocimiento de la alteridad. Es pertinente mencionar aquí lo expuesto por Ch. TAYLOR en su último libro, $A$ Secular Age, en el que define la secularización como una época en la que la opción por defecto (default option) de los ciudadanos por lo que se refiere a su adscripción religiosa no es la adhesión al credo de sus progenitores, sino la apropiación libre de las creencias religiosas que consideren más adecuadas a sus intereses, necesidades o intuiciones cognitivas: «Mi propia visión de la "secularización" que, confieso libremente, ha sido conformada por mi propia perspectiva como creyente (pero que, con todo, quisiera esperar ser capaz de defender con argumentos), es que ha habido ciertamente un "declive" de la religión. La creencia religiosa existe abora en un campo de elección que incluye varias formas de objeción y rechazo; la fe cristiana existe en un campo en el que también hay un amplio abanico de otras opciones espirituales» ${ }^{37}$. Este nuevo campo de elección, esta nueva forma de bricolaje espiritual que caracteriza al vínculo religioso en las sociedades contemporáneas, es alentado por los currícula escolares en la medida en que

36 Cfr. también las ya clásicas sentencias Zengin vs. Turquía (46928/99) y Folgerø vs. Noruega (15472/02).

37 Ch. TAYlor, A Secular Age, Cambridge (Mass.) y London, Harvard University Press, 2007, 437 (mi cursiva). 
en éstos se familiariza a los alumnos con las tendencias espirituales presentes en la sociedad. De modo que el conocimiento recíproco que se persigue con estas asignaturas puede tener consecuencias para la libertad positiva de los futuros ciudadanos, ya que este conocimiento no sólo sirve para facilitar la tolerancia recíproca en sociedad, sino también para aportar contenidos de modo que su eventual elección espiritual sea más informada.

La disonancia cognitiva, en una sociedad en la que la religión no es la argamasa que religa a la sociedad, sino un vínculo personal, es la norma. La dimensión religiosa del desarrollo personal es, así, tomada en consideración por la escuela, aunque sólo sea como efecto secundario de la introducción de asignaturas como la de historia de las religiones, o las relativas al «hecho religioso».

En segundo lugar y ya para acabar, es preciso destacar los presupuestos «culturalistas» de la enseñanza del hecho religioso. Si atendemos a la justificación de estas asignaturas en términos del conocimiento recíproco que fomenta y del ideal de ciudadanía que de este modo se persigue, observaremos que uno de los problemas que se suscitan es el reduccionismo religioso. A. SEN lo presenta en su libro Identidad y violencia, en el que rechaza la compartimentación social desde una perspectiva religiosa, así como la uniformización externa de los colectivos bajo parámetros religiosos o culturales. La cultura como cautiverio, señala SEN, impide ver otros elementos que conforman las identidades individuales al homogeneizar lo heterogéneo ${ }^{38}$. De ahí que, si bien la educación religiosa puede contribuir a conocer al vecino, puede también conllevar que éste no sea visto más que como portador de los estereotipos con los que se decodifica al otro por parte de los miembros de la cultura hegemónica. Estas críticas se pueden aplicar a la creencia que la educación religiosa puede ayudar a mejorar la coexistencia, pues de este modo se presupone que la manera de contribuir al conocimiento de las personas y de los grupos sociales consiste en familiarizarse con su religión; algo que tal vez sólo sea cierto para los ojos que miran y no para los que son vistos.

Este modelo corre el riesgo de caer en los mismos problemas que puede provocar una aplicación estricta del «derecho que asiste a los padres para que sus hijos reciban la formación religiosa y moral que esté de acuerdo con sus propias convicciones» (Constitución Española, 27.3). Derecho que se garantiza en España, si bien su implementación no ha sido aún realizada plenamente, y que ha sido también motivo de discusión en Italia, si bien ahí ha prevalecido, hasta la fecha, el miedo a que «los estudiantes perciban la religión como algo que los divide, incluso físicamente, con los católicos en un aula y los musulmanes en otra. Cada cual se sentiría no tanto confirmado en la propia identidad, sino más bien encerrado en un recinto al cual los otros no pueden entrar» ${ }^{39}$. Y se pasaría así «de la hora de religión a la hora de las religiones» ${ }^{40}$.

38 A. SEN, Identidad y violencia, Buenos Aires, Katz, 2007, 156 y ss. Esta tendencia se manifiesta en las palabras de SARKOZY: «La religión no es un mero fenómeno cultual. Es también un elemento de identidad cultural. [...] La renuncia o la indiferencia respecto de una adscripción religiosa equivale casi a desolidarizarse de una comunidad a la que se pertenece por nacimiento, como quien abandona una herencia o una faceta de su propia vida» (SARKOZY, 2006: 30). Es remarcable que mientras, de una parte, SARKOZY nos precave de la «tentación de un repliegue», de la «tentación comunitaria», de la otra, no duda en hipostatizar las comunidades religiosas.

39 S. Rodotà, Perché laico, Roma, Laterza, 2009, 153.

40 Rodotà, 2009: 155. 
Mientras que la «hora de religión», confesional y voluntaria, puede conllevar una división dentro de las escuelas basada en la lectura de las culturas ( $i y$ de los individuos!) en clave religiosa, no contribuyendo, por tanto, al reconocimiento recíproco; la «hora de las religiones», entendida como aprendizaje del «hecho religioso», es decir, con obligatoriedad curricular para todos, sin divisiones ni posibilidad de exenciones, contribuiría a relativizar la pretensión de validez universal de las religiones que aspiran aún a la hegemonía, y aunque no es seguro que ayudara al conocimiento recíproco, en todo caso aportaría algo del sano escepticismo cívico recomendado por MILL anteriormente, y contribuiría a la reforma de las mismas instituciones religiosas, a la transformación de lo dado. Algo que, por otra parte, viene propuesto desde hace tiempo por los pedagogos que ven en la perspectiva intercultural una solución para las sociedades diversas ${ }^{41}$.

41 El conocimiento transformativo es el que cuestiona y desafía los lugares comunes de la cultura establecida. Para enfrentarse a los nuevos desafíos del mundo contemporáneo es necesaria, así pues, una «educación multicultural transformativa», $c f r$. J. A. BANKS, «The Canon Debate, Knowledge Construction, and Multicultural Education», en J. A. BANKS (ed.), Multicultural Education, Transformative Knowledge and Action, New York, Teachers College Press, 1996; 9-29, 22. 